\title{
In silico pathway analysis and tissue specific cis-eQTL for colorectal cancer GWAS risk variants
}

\author{
Lenora W. M. Loo ${ }^{1 *}$, Mathieu Lemire ${ }^{2}$ and Loïc Le Marchand ${ }^{1}$
}

\begin{abstract}
Background: Genome-wide association studies have identified 55 genetic variants associated with colorectal cancer risk to date. However, potential causal genes and pathways regulated by these risk variants remain to be characterized. Therefore, we performed gene ontology enrichment and pathway analyses to determine if there was an enrichment of genes in proximity to the colorectal cancer risk variants that could further elucidate the probable causal genes and pathways involved in colorectal cancer biology.

Results: For the 65 unique genes that either contained, or were immediately neighboring up- and downstream, of these variants there was a significant enrichment for the KEGG pathway, Pathways in Cancer ( $p$-value $=2.67 \times 10^{-5}$ ) and an enrichment for multiple biological processes (FDR $<0.05$ ), such as cell junction organization, tissue morphogenesis, regulation of SMAD protein phosphorylation, and odontogenesis identified through Gene Ontology analysis. To identify potential causal genes, we conducted a cis-expression quantitative trait loci (cis-eQTL) analysis using gene expression and genotype data from the Genotype-Tissue Expression (GTEx) Project portal in normal sigmoid $(n=124)$ and transverse $(n=$ 169) colon tissue. In addition, we also did a cis-eQTL analysis on colorectal tumor tissue $(n=147)$ from The Cancer Genome Atlas (TCGA). We identified two risk alleles that were significant cis-eQTLs for FADS2 (rs1535) and COLCA1 and 2 (rs3802842) genes in the normal transverse colon tissue and two risk alleles that were significant cis-eQTLs for the CABLES2 (rs2427308) and LIPG (rs7229639) genes in the normal sigmoid colon tissue, but not tumor tissue.
\end{abstract}

Conclusions: Our data reaffirm the potential to identify an enrichment for biological processes and candidate causal genes based on expression profiles correlated with genetic risk alleles of colorectal cancer, however, the identification of these significant cis-eQTLs is context and tissue specific.

Keywords: Colorectal cancer, eQTL, Risk variant, Gene expression

\section{Background}

According to the Centers for Disease Control and Prevention, in 2012 colorectal cancer (CRC) was the third most common cancer worldwide, with an estimated 1.4 million individuals diagnosed with CRC (www.cdc.gov). As a result, $\mathrm{CRC}$ is the fourth most common cause of cancer-related death, with 694,000 individuals dying from colorectal cancer annually. Risk of CRC is influenced by both environmental and genetic factors. A small percentage of CRC (3-5\%) has been associated with high penetrance germline mutations, primarily contributing to the familial forms of CRC.

\footnotetext{
* Correspondence: Iloo@cc.hawaii.edu

${ }^{1}$ Cancer Epidemiology Program, University of Hawaii Cancer Center, Honolulu, HI, USA

Full list of author information is available at the end of the article
}

Whereas for sporadic CRC, genome-wide association studies (GWAS) have to date identified 55 risk variants, each associated with a modest increase in risk of developing CRC.

Overall, GWAS involving thousands of cases and controls have identified hundreds of genetic variants associated with cancer or other diseases [1,2]; however, the majority of these risk alleles are associated with a modest disease risk $(\mathrm{OR}<1.5)$ [1]. One can anticipate that additional susceptibility variants will be identified through studies that have increased sample sizes, studies focusing on specific molecular sub-types, studies on other races/ethnicities, such as African Americans, Latinos and Asians, and with the application of high-throughput sequencing technologies to fine map the association signals. However, the current understanding of the biological contributions of these risk alleles 
has been limited. Progress has recently been made on the functional characterization of these putative causal variants through the application of tools and databases, such as expression quantitative trait loci (eQTL) analysis with the Genotype-Tissue Expression (GTEx) Project portal [3], identification of genomic modifications involved in gene regulation by the Encyclopedia of DNA Elements (ENCODE) Consortium [4], and the integration of highresolution molecular characterization of multiple cancers by The Cancer Genome Atlas (TCGA) [5] (http://cancergenome.nih.gov/).

In this study, we conducted a Gene Ontology and pathway analysis of the genes containing, or neighboring, the 55 GWAS risk alleles for CRC in order to identify potential functional mechanisms or biological pathways that could be regulated in cis by these risk alleles. We also conducted a cis-eQTL analysis to examine the relationship between the CRC risk variants and gene expression for normal colon (sigmoid and transverse) and colorectal tumor tissue utilizing the GTEx Project portal and TCGA data, respectively.

\section{Methods}

\section{Risk variants}

Colorectal cancer GWAS risk variants were identified in the National Human Genome Research Institute (NHGRI) European Bioinformatics Institute (EBI) catalog of published GWAS (https://www.ebi.ac.uk/gwas/ home; $\mathrm{p} \leq 5 \times 10^{-8}$; April 2016) [1].

\section{Expression quantitative trait loci analysis}

The GTEx project portal (http://www.gtexportal.org/ home/) was used to identify cis-eQTLs in normal transverse and sigmoid colon tissue for CRC risk variants (April 2016) [3]. Briefly, the cis-eQTL mapping window was defined as 1 megabase up- and downstream of the transcription start site. False discovery rate (FDR) was used for multiple hypothesis test correction [6]. Significant cis-eQTLs were identified based on false discovery rate FDR q-values $\leq 0.05$. The effect size of the eQTL was defined as the slope of the linear regression-computed as the effect of the alternate allele relative to the reference allele.

We evaluated cis-eQTL using data from TCGA which consists of gene expression and genotype data from 155 colon adenocarcinomas and 19 normal colon tissues (from a total of 162 distinct donors: 12 matched tumor and normal adjacent pairs are included). Gene expression data was derived from an Agilent $244 \mathrm{~K}$ Custom Gene Expression Array and genotypes were derived from Affymetrix Genome-Wide Human SNP 6.0 Array. We used Level 3 expression data (publicly available), which consists of normalized signals and expression calls per gene, per sample. Genotype data were obtained under approved access. Gene expression levels were compared between genotypes or between normal and tumor tissues using the non-parametric Wilcoxon rank sum test when comparing two factors or Kruskal Wallis test when comparing three factors.

\section{Bioinformatics analysis and databases}

Potential functional annotation of the risk alleles were identified using the HaploReg version 4.1database (www.broadinstitute.org/mammals/haploreg; [7, 8]). The position weight matrices modeling to examine the effects of the risk allele on transcription factor binding in HaploReg was collected from TRANSFAC [9] and JASPAR [10] databases. Transcriptional regulatory features such as DNase sensitivity, histone modifications, and transcription factor binding were examined in the University of California Santa Cruz (UCSC) Encyclopedia of DNA Elements (ENCODE) database (https://www.encodeproject.org/). The Polymorphism Phenotyping v2 (PolyPhen-2) tool was used to annotate the potential effects on protein function of coding (nonsynonymous) SNPs (http://genetics.bwh. harvard.edu/pph2/; [11]). This tool was applied to estimate the probability of the resulting amino acid substitution having a damaging effect to the protein product function. The Database for Annotation Visualization and Integrated Discovery (DAVID) v6.7 was used to identify an enrichment of biological themes, particularly Gene Ontology terms, and Kyoto Encyclopedia of Genes and Genomes (KEGG) pathways (https://david.ncifcrf.gov/ home.jsp; [12, 13]).

\section{Results}

To date, 55 risk variants have been associated with colorectal cancer in GWAS ( $\mathrm{p} \leq 5 \times 10^{-8}$ ). Of these, two are coding SNPs, one synonymous (rs10936599) and one missense (rs3184504), 26 are intronic, and 27 intergenic SNPs (Table 1).

\section{Gene ontology enrichment analysis of genes neighboring colorectal cancer risk alleles}

To determine if the 55 CRC risk variants were located in or near genes that shared similar molecular functions, or functioned in a common biological pathway, we performed gene ontology enrichment and pathway analysis of the 65 unique genes that were immediately neighboring up- and downstream of these variants. The KEGG Pathway that was significantly $($ FDR $\leq 0.05)$ enriched was Pathways in Cancer $\left(p\right.$-value $\left.=2.67 \times 10^{-5}\right)$. This pathway was enriched 6.34-fold, with 9 genes neighboring the CRC risk alleles listed in this pathway: BMP4,CDKN1A, BMP2, LAMA5, CDH1, LAMC1, TCF7L2, TGFB1, and CTNNB1. Gene Ontology analysis identified an enrichment for multiple biological processes (FDR $\leq$ 
Table 1 Colorectal cancer risk variants

\begin{tabular}{|c|c|c|c|c|c|c|c|}
\hline SNPS & $\begin{array}{l}\text { Risk } \\
\text { Allele }\end{array}$ & Locus & Gene(s) & $\begin{array}{l}\text { Genomic } \\
\text { position }\end{array}$ & $p$-value & OR $[95 \% \mathrm{Cl}]$ & Reference \\
\hline rs10911251 & A & $1 \mathrm{q} 25.3$ & LAMC1 & Intron & $2 \times 10^{-8}$ & $1.09[1.06-1.12]$ & {$[45,46]$} \\
\hline rs6691170 & $\mathrm{T}$ & $1 q 41$ & $\begin{array}{l}\text { DUSP10 - } \\
\text { HHIPL2 }\end{array}$ & Intergenic & $1 \times 10^{-9} ; 9.6 \times 10^{-10}$ & $1.06[1.03-1.09] ; 1.06$ [1.03-1.09] & {$[47,48]$} \\
\hline rs6687758 & G & $1 q 41$ & $\begin{array}{l}\text { DUSP10 - } \\
\text { HHIPL2 }\end{array}$ & Intergenic & $2 \times 10^{-9} ; 2.3 \times 10^{-9}$ & $1.09[1.06-1.12] ; 1.09[1.06-1.12]$ & {$[47,48]$} \\
\hline rs11903757 & $C$ & $2 q 32.3$ & NABP1-SDPR & Intergenic & $4 \times 10^{-8}$ & $1.16[1.10-1.22]$ & [45] \\
\hline rs35360328 & $\mathrm{A} / \mathrm{T}$ & $3 p 22.1$ & $\begin{array}{l}\text { ZNF621- } \\
\text { CTNNB1 }\end{array}$ & Intergenic & $3.1 \times 10^{-9}$ & $1.14[1.09-1.19]$ & [49] \\
\hline rs812481 & $\mathrm{G} / \mathrm{C}$ & $3 p 14.1$ & $L R|G|$ & Intron & $2 \times 10^{-8}$ & $1.09[1.05-1.11]$ & [49] \\
\hline rs10936599 & C & $3 q 26.2$ & MYNN & Synonymous & $3 \times 10^{-8} ; 3.4 \times 10^{-8}$ & 1.04 [1.04-1.10]; 0.93 [0.91-0.96] & {$[48,50]$} \\
\hline rs35509282 & A & $4 q 32.2$ & FSTL5 - NAF1 & Intergenic & $8.2 \times 10^{-9}$ & $1.53[\mathrm{NR}]$ & {$[51]$} \\
\hline rs367615 & $?$ & $5 q 21.3$ & PJA2-MAN2A1 & Intergenic & $4 \times 10^{-8}$ & $1.35[1.20-1.49]$ & {$[52]$} \\
\hline rs647161 & A & $5 q 31.1$ & C5orf66 & Intron & $\begin{array}{l}1 \times 10^{-10} ; 4 \times 10^{-10} \\
\text { (East Asian); } 1.2 \times 10^{-10}\end{array}$ & $\begin{array}{l}1.11[1.08-1.15] ; 1.17[1.11-1.22] \\
\text { (East Asian); } 1.11[1.08-1.15]\end{array}$ & {$[48,53]$} \\
\hline rs1321311 & A & $6 p 21.2$ & SRSF3-CDKN1A & Intergenic & $1 \times 10^{-10} ; 1.1 \times 10^{-10}$ & $1.10[1.07-1.13] ; 1.10[1.07-1.13]$ & {$[48,54]$} \\
\hline rs7758229 & $\mathrm{T}$ & $6 q 25.3$ & SLC22A3 & Intron & $8 \times 10^{-9} ; 7.9 \times 10^{-9}$ & 1.28 [1.18-1.39]; 1.28 [1.18-1.39] & {$[48,55]$} \\
\hline rs16892766 & A & $8 q 23.3$ & TRPS1-EIF3H & Intergenic & $3 \times 10^{-18} ; 3.3 \times 10^{-18}$ & $1.27[1.20-1.34] ; 1.25$ [1.19-1.32] & {$[48,56]$} \\
\hline rs140355816 & G & $8 q 23.3$ & TRPS1-EIF3H & Intergenic & $2 \times 10^{-8}$ & 1.59 [NR] & {$[46]$} \\
\hline rs10505477 & A & $8 q 24.21$ & $\begin{array}{l}\text { FAM84B- } \\
\text { POU5F1B }\end{array}$ & Intron & $3.2 \times 10^{-11}$ & $1.17[1.12-1.23]$ & {$[48,57]$} \\
\hline rs6983267 & G & $8 q 24.21$ & $\begin{array}{l}\text { FAM84B - } \\
\text { POU5F1B }\end{array}$ & ncRNA;intron & $1 \times 10^{-11} ; 7 \times 10^{-11} ; 1 \times 10^{-14}$ & $\begin{array}{l}1.13[1.09-1.18] ; 1.24[1.17-1.33] ; 1.27 \\
\mid[1.16-1.39]\end{array}$ & $\begin{array}{l}{[45,48,55,} \\
56,58]\end{array}$ \\
\hline rs7014346 & $A$ & $8 q 24.21$ & $\begin{array}{l}\text { FAM84B - } \\
\text { POU5F1B }\end{array}$ & Intron & $8.6 \times 10^{-26}$ & $1.19[1.14-1.24]$ & {$[48,59]$} \\
\hline rs10795668 & $A$ & 10p14 & GATA3-CELF2 & Intergenic & $3 \times 10^{-13} ; 2.5 \times 10^{-13}$ & 1.12 [1.10-1.16]; 0.89 [0.86-0.91] & {$[48,56]$} \\
\hline rs11255841 & T & 10p14 & GATA3-CELF2 & Intergenic & $7 \times 10^{-11}$ & $1.19[N R\}$ & {$[46]$} \\
\hline rs704017 & G & $10 \mathrm{q} 22.3$ & RPS24-ZMIZ1 & Intergenic & $2 \times 10^{-8}$ & $1.10[1.06-1.13]$ & {$[22]$} \\
\hline rs11190164 & $\mathrm{G} / \mathrm{A}$ & $10 q 24.2$ & $\begin{array}{l}\text { NKX2-3- } \\
\text { SLC25A28 }\end{array}$ & Intergenic & $4.0 \times 10^{-8}$ & $1.09[1.06-1.12]$ & [49] \\
\hline rs1035209 & $\mathrm{T}$ & $10 q 24.2$ & $\begin{array}{l}\text { NKX2-3- } \\
\text { SLC25A28 }\end{array}$ & Intergenic & $5 \times 10^{-11}$ & $1.12[1.08-1.16]$ & {$[46]$} \\
\hline rs12241008 & C & $10 q 25$ & VTI1A & Intron & $1.4 \times 10^{-9}$ & $1.13[1.09-1.18]$ & {$[60]$} \\
\hline rs11196172 & A & $10 \mathrm{q} 25.2$ & TCF7L2 & Intron & $1 \times 10^{-12}$ & $1.14[1.10-1.18]$ & {$[22]$} \\
\hline rs3824999 & C & $11 q 13.4$ & POLD3 & Intron & $4 \times 10^{-10} ; 3.7 \times 10^{-10}$ & 1.08 [1.05-1.10]; $0.93[0.91-0.95]$ & {$[48,54]$} \\
\hline rs3802842 & C & $11 q 23.1$ & $\begin{array}{l}\text { COLCA2 - } \\
\text { COLCA1 }\end{array}$ & Intron & $5.8 \times 10^{-10}$ & $1.11[1.08-1.15]$ & {$[48,61]$} \\
\hline rs174537 & G & $11 q 12.2$ & MYRF & Intron & $9 \times 10^{-21}$ & $1.16[1.12-1.19]$ & {$[22]$} \\
\hline rs1535 & A & $11 q 12.2$ & FADS2 & Intron & $8 \times 10^{-20}$ & 1.09 [1.04-1.13] & {$[22]$} \\
\hline rs10774214 & $\mathrm{T}$ & $12 \mathrm{p} 13.32$ & $\begin{array}{l}\text { PARP11 - } \\
\text { CCND2 }\end{array}$ & Intergenic & $3 \times 10^{-8} ; 5 \times 10^{-10}$ & $1.09[1.06-1.13] ; 1.17[1.11-1.23]$ & {$[48,53]$} \\
\hline rs7136702 & $\mathrm{T}$ & $12 q 13.13$ & LARP4 - DIP2 & Intergenic & $4.0 \times 10^{-8}$ & $1.06[1.04-1.08]$ & {$[48,50]$} \\
\hline rs10849432 & $\mathrm{T}$ & 12p13.31 & CD9- PLEKHG6 & Intergenic & $6 \times 10^{-10}$ & $1.14[1.09-1.18]$ & {$[22]$} \\
\hline rs34245511 & C & $12 q 13.12$ & LIMAI & Intron & $3 \times 10^{-8}$ & $1.14[N R\}$ & {$[46]$} \\
\hline rs11169552 & C & $12 q 13.12$ & DIP2B - ATF1 & Intergenic & $2 \times 10^{-10} ; 1.9 \times 10^{-10}$ & 1.09 [1.05-1.11]; $0.92[0.90-0.95]$ & {$[48,50]$} \\
\hline rs3217810 & $\mathrm{T}$ & $12 p 13.32$ & CCND2 & Intron & $2 \times 10^{-10}$ & $1.10[1.06-1.14]$ & {$[45,46]$} \\
\hline rs10774214 & $\mathrm{T}$ & $12 p 13.32$ & CCND2 & Intron & $5 \times 10^{-10}$ & $1.17[1.11-1.23]$ & [53] \\
\hline rs3184504 & C & $12 q 24.12$ & $\mathrm{SH} 2 \mathrm{~B} 3$ & Missense & $1.7 \times 10^{-8}$ & $1.09[1.06-1.12]$ & [49] \\
\hline
\end{tabular}


Table 1 Colorectal cancer risk variants (Continued)

\begin{tabular}{|c|c|c|c|c|c|c|c|}
\hline rs73208120 & G & $12 q 24.22$ & NOS1 & Intron & $2.8 \times 10^{-8}$ & $1.16[1.11-1.23]$ & [49] \\
\hline rs4444235 & C & $14 q 22.2$ & DDHD1 - BMP4 & Intergenic & $8 \times 10^{-10}$ & $1.11[1.08-1.15]$ & {$[47,48,56]$} \\
\hline rs1957636 & A & $14 q 22.2$ & BMP4 - CDKN3 & Intergenic & $1 \times 10^{-9}$ & 1.08 [1.06-1.11] & [62] \\
\hline rs17094983 & A & $14 q 23.1$ & $\begin{array}{l}\text { DACT1 - } \\
\text { PRL31P4 }\end{array}$ & Intergenic & $2.5 \times 10^{-10}$ & $0.87[0.83-0.91]$ & [63] \\
\hline rs4779584 & $\mathrm{T}$ & $15 q 13.3$ & SCG5 - GREM1 & Intergenic & $2 \times 10^{-8} ; 4.4 \times 10-{ }^{14}$ & $1.18[1.11-1.24] ; 1.26[1.19-1.34]$ & {$[48,64]$} \\
\hline rs73376930 & G & $15 q 13.3$ & GREM1 & Intron & $1.010^{-11}$ & $1.246[\mathrm{NR}]$ & [46] \\
\hline rs9929218 & G & $16 q 22.1$ & $\mathrm{CDH} 1$ & Intron & $1 \times 10^{-8} ; 1.2 \times 10^{-8}$ & 1.10 [1.06-1.12]; 0.91 [0.89-0.94] & {$[47,48]$} \\
\hline rs12603526 & C & $17 p 13.3$ & NXN & Intron & $3 \times 10^{-8}$ & $1.10[1.06-1.14]$ & [22] \\
\hline rs7229639 & A & $18 q 21.1$ & SMAD7 & Intron & $2 \times 10^{-8}$ & $1.20[1.16-1.25]$ & {$[22]$} \\
\hline rs4939827 & $\mathrm{T}$ & $18 q 21.1$ & SMAD7 & Intron & $\begin{array}{l}2 \times 10^{-10} ; 8 \times 10^{-28} ; 1 \times 10 \\
-12 ; 1 \times 10^{-12}\end{array}$ & $\begin{array}{l}1.12[1.09-1.16] ; 1.20[1.16-1.24] ; \\
1.16[1.09-1.27] ; 0.85[0.81-0.89]\end{array}$ & $\begin{array}{l}{[48,61,64,} \\
65]\end{array}$ \\
\hline rs10411210 & C & $19 q 13.11$ & RHPN2 & Intron & $5 \times 10^{-9} ; 4.6 \times 10^{-9}$ & $1.15[1.10-1.20] ; 0.87[0.83-0.91]$ & {$[47,48]$} \\
\hline rs1800469 & G & $19 q 13.2$ & TGFB1- B9D2 & Intergenic & $1 \times 10^{-8}$ & $1.09[1.06-1.12]$ & [22] \\
\hline rs961253 & A & 20p12.3 & $\begin{array}{l}\text { FERMT1 - } \\
\text { BMP2 }\end{array}$ & Intergenic & $2 \times 10^{-10}$ & $1.12[1.08-1.16]$ & {$[47,48]$} \\
\hline rs2423279 & C & $20 p 12.3$ & $B M P 2-H A O 1$ & Intergenic & $6.64 \times 10^{-9}$ & $1.10[1.06-1.14]$ & {$[48,53]$} \\
\hline rs4813802 & G & $20 p 12.3$ & CASC2O - BMP2 & Intergenic & $7 \times 10^{-11}$ & $1.10[1.06-1.12]$ & {$[62,64]$} \\
\hline rs6066825 & G & $20 q 13.1$ & PREX1 & Intron & $4.41 \times 10^{-9}$ & $1.09[1.06-1.12]$ & [49] \\
\hline rs4925386 & C & $20 q 13.33$ & LAMA5 & Intron & $2 \times 10^{-10} ; 1.9 \times 10^{-10}$ & $1.08[1.05-1.10] ; 0.93[0.91-0.95]$ & {$[48,50]$} \\
\hline rs2427308 & C & $20 q 13.33$ & CABLES2 & Intron & $3 \times 10^{-11}$ & $1.24[\mathrm{NR}]$ & {$[46]$} \\
\hline rs5934683 & C & Xp22.2 & $\begin{array}{l}\text { GPR143 - } \\
\text { SHROOM2 }\end{array}$ & Intergenic & $7.3 \times 10^{-10}$ & $1.07[1.04-1.10]$ & {$[48,54]$} \\
\hline
\end{tabular}

0.05), such as cell junction organization, tissue morphogenesis, regulation of SMAD protein phosphorylation, and odontogenesis (Table 2). The Gene Ontology molecular function category also identified beta-catenin $\left(p\right.$-value $\left.=1.38 \times 10^{-4}\right)$ and SMAD binding ( $p$-value $=0.01)$; however, both were no longer statistically significant after correction for multiple-testing $($ FDR > 0.05).

\section{cis-eQTL analysis for colorectal cancer risk alleles}

We also conducted a search for cis-eQTL $($ FDR $\leq 0.05)$ among the CRC risk alleles using data for both normal sigmoid ( $n=124$ samples) and transverse $(n=169$ samples) colon tissue from the GTEx Project portal (Additional file 1: Table S1) and followed up significant results in colorectal tumor tissue ( $n=155$ samples) from TCGA. Of the 55 risk alleles and 65 unique genes queried in colorectal normal and tumor tissue, we identified 3 intronic risk alleles (rs1535, rs3802842, rs2427308) that were statistically significant cis-eQTLs for the gene containing the risk variant in normal colon tissue. We also identified two intronic risk alleles (rs34245511 and rs7229639) that were a statistically significant cis-eQTLs for genes neighboring the intronic SNPs, but not for the gene containing the SNP. Results are described separately for each of these risk variants below and transcriptional regulatory features [7] summarized in Additional file 2: Table S2.

\section{rs1535}

The CRC risk allele for rs1535 is located at 11q12. A significant cis-eQTL $\left(p=1.80 \times^{-10}\right)$ for the fatty acid desaturase 2

Table 2 Gene Ontology Analysis - Biological Process

\begin{tabular}{|c|c|c|c|c|}
\hline GO term & Genes & Fold enrichment & $p$-value & FDR \\
\hline GO:0034330 cell junction organization & $\begin{array}{l}\text { CD9, SHROOM2, SMAD7, } \\
\text { LAMA5, LAMC1, TGFB1 }\end{array}$ & 29.06 & $1.66 \times 10^{-6}$ & 0.003 \\
\hline GO:0001763 morphogenesis of a branching structure & $\begin{array}{l}\text { BMP4, BMP2, LAMA5, } \\
\text { GREM1, TGFB1, CTNNB1 }\end{array}$ & 22.38 & $6.09 \times 10^{-6}$ & 0.010 \\
\hline GO:0060393 regulation of pathway-restricted SMAD protein phosphorylation & $B M P 4, B M P 2, S M A D 7, T G F B 1$ & 64.96 & $2.75 \times 10^{-5}$ & 0.044 \\
\hline GO:0002009 morphogenesis of an epithelium & $\begin{array}{l}\text { BMP4, BMP2, LAMA5, } \\
\text { GREM1, CTNNB1, NKX2-3 }\end{array}$ & 16.40 & $2.79 \times 10^{-5}$ & 0.045 \\
\hline
\end{tabular}


(FADS2) gene was identified for normal transverse colon tissue. The risk allele was associated with lower expression levels of FADS2 compared to the reference allele, with an effect size of $E S=0.36$ (Fig. 1a). Interestingly, there were other multiple significant cis-eQTLs for the FADS2 gene located within and in neighboring regions outside of the FADS2 gene for normal transverse colon tissue (Fig. 1b), with rs61897795, not rs1535, being the most significant ciseQTL for the FADS2 gene $\left(p=2.40 \times 10^{-18} ; \mathrm{ES}=0.64\right)$. The two SNPs have an LD of $\mathrm{r}^{2}=0.32$ (Europeans) and are located over $20 \mathrm{~Kb}$ apart, with rs1535 located in intron 1 and rs61897795 in intron 5 of the FADS2 gene. In addition, other significant cis-eQTLs for FADS2 were identified in multiple tissue types (Fig. 1c). The most significant is observed in whole blood for rs968567 $\left(p=7.00 \times 10^{-71}\right)$ with a strong effect size $(\mathrm{ES}=1.4)$. rs968567 is located in the 5'UTR of the FADS2 gene and is also a significant cis-eQTL in both normal transverse $\left(p=4.83 \times 10^{-13}\right.$; $\left.\mathrm{ES}=0.60\right)$ and sigmoid $\left(p=1.10 \times 10^{-7} ; \mathrm{ES}=0.68\right)$ colon tissue. The protein product of the FADS 2 gene is delta- 6 desaturase. It is a member of the fatty acid desaturase gene family and catalyzes the first and rate-limiting step in the biosynthesis of long chain polyunsaturated fatty acid (PUFA).

We also queried TCGA to determine if rs1535 was also a cis-eQTL in colorectal tumor tissue. We utilized the TCGA dataset of CRC patients $(n=155)$ with available genotype $(n=147)$ and gene expression information. Because the SNP data available for the TCGA samples did not include genotypes for rs1535, a proxy (rs174547) in high LD $\left(\mathrm{r}^{2}=\right.$ 0.96; Europeans) was used for this analysis. We confirmed from the GTEx Project portal that it was also a significant cis-eQTL for FADS2 $\left(p=1.00 \times 10^{-10}\right)$ in normal transverse colon tissue. We found that the proxy risk allele was associated with lower expression levels in colorectal tumor tissue compared to the reference allele $\left(p=1.5 \times 10^{-4}\right)$.

Available ENCODE data indicate that rs1535 is located in a region with transcriptional regulatory activity based on DNAse sensitivity and chromatin states in cell lines and in colon tissue analysis (Additional file 3: Figure S1). Histone marks (H3K4me1_Enh and H3K27ac_Enh) are detected at the locus, suggesting that this locus may function as an enhancer in the colon and other related gastrointestinal tissue. In addition, based on the 25-state chromatin model, the locus is predicted to have promoter function (4PromD2) and transcription factor chromatin immunoprecipitation sequencing (ChIP-seq) assays identified estrogen receptor alpha (ESR1) binding to the locus. Based on position weight matrix modeling, the risk allele is estimated to have a weaker affinity for ESR1 binding compared to the reference allele at rs1535.

\section{rs3802842}

The CRC risk variant, rs3802842, is located at 11q23 in the intronic regions of two overlapping genes, the colorectal cancer associated 2 and 1 (COLCA2 and COLCA1) genes. rs3802842 was identified in the GTEx Project as a significant cis-eQTL in normal transverse colon tissue for both COLCA2 $\left(p=2.9 \times 10^{-26}\right)$ and COLCA1 $\left(p=1.2 \times 10^{-20}\right)$. The risk allele is associated with lower expression levels of both genes in the normal transverse colon tissue compared to the reference allele, with an effect size of $E S=-0.77$ and $E S=-0.70$ for COLCA2 and COLCA1, respectively (Fig. 2a box plots). rs3802842 was also a significant cis-eQTL for the neighboring gene, C11orf53 ( $p=1.1 \times 10^{-15}$; ES = -0.46) in normal transverse colon tissue. In addition, based on the GTEx analysis, there were multiple cis-eQTLs for the COLCA2 and COLCA1 genes in the normal transverse colon tissue (Fig. 2b). However, the risk allele, rs3802842, was not the most significant eQTL for COLCA2, COLCA1, and C11orf53. rs7130173, a SNP in high LD $\left(\mathrm{r}^{2}\right.$ $=0.94$; Europeans) with the risk allele, was the most significant cis-eQTL for COLCA2 $\left(p=1.50 \times 10^{-26}\right.$; ES = -0.78 ) and therefore, may be a better candidate causal allele. The two SNPs are located over $17 \mathrm{~Kb}$ apart, with rs3802842 located in intron 2 of the COLCA2 gene and rs7130173 located in intron 3 of the neighboring C11orf53 gene. Similarly, rs3087967, a SNP in high $\mathrm{LD}\left(\mathrm{r}^{2}=0.95\right.$; Europeans) with the risk allele is the most significant ciseQTL $\left(p=4.4 \times 10^{-21}\right.$; ES = 0.71) for COLCA1 in normal transverse colon tissue. It is $14.8 \mathrm{~Kb}$ apart from the published risk allele and located in the 3'-UTR of C11orf53. Based on the GTEx Project data for multiple tissue types $(n=44)$, the associated effects on gene expression between rs3802842 and the three genes (COLCA2, COLCA1, and C11orf53) in the normal transverse colon tissue was specific for this tissue, it was not observed in the other 43 tissue types included in the GTEx Project. The only other significant association for rs3802842 and expression of COLCA2 was in the tibial artery and for COLCA1 in tibial nerve tissue (Fig. 2c).

We also did a cis-eQTL analysis for rs3802842 in colorectal tumor tissue using the TCGA dataset. Because the SNP data available for the TCGA samples did not include rs3802842, a proxy SNP (rs3802840) in high LD $\left(\mathrm{r}^{2}=1.0\right.$; Europeans) with the risk variant was queried. The proxy risk allele, GTEx Project portal showed that it was also a significant cis-eQTL in normal transverse colon tissue for COLCA2 $\left(p=2.9 \times 10^{-26}\right)$, COLCA1 $\left(p=1.2 \times 10^{-20}\right)$, and C11orf53 $\left(p=1.1 \times 10^{-15}\right)$. The cis-eQTL analysis with the proxy SNP demonstrated similar expression patterns in the colorectal tumor tissue samples, where the risk allele associated with lower expression levels compared to the reference allele for the COLCA2 $\left(p=8.90 \times 10^{-4}\right)$ and COLCA1 $\left(p=4.70 \times 10^{-3}\right)$ genes (Additional file 4: Figure S2).

rs3802842 is located in intronic regions of both COLCA2 and COLCA1 and based on chromatin profiling of the locus, histone marks (H3K4me1_Enh, H3K4me3_Pro, and 
a

FADS2 (rs1535)

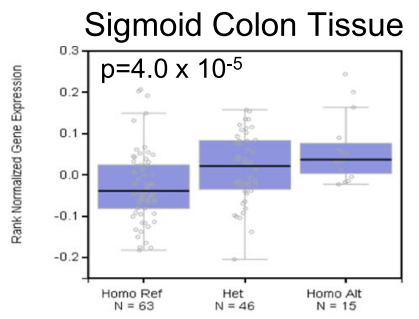

Transverse Colon Tissue

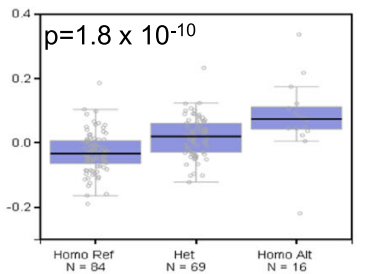

FADS1 (rs1535)

b
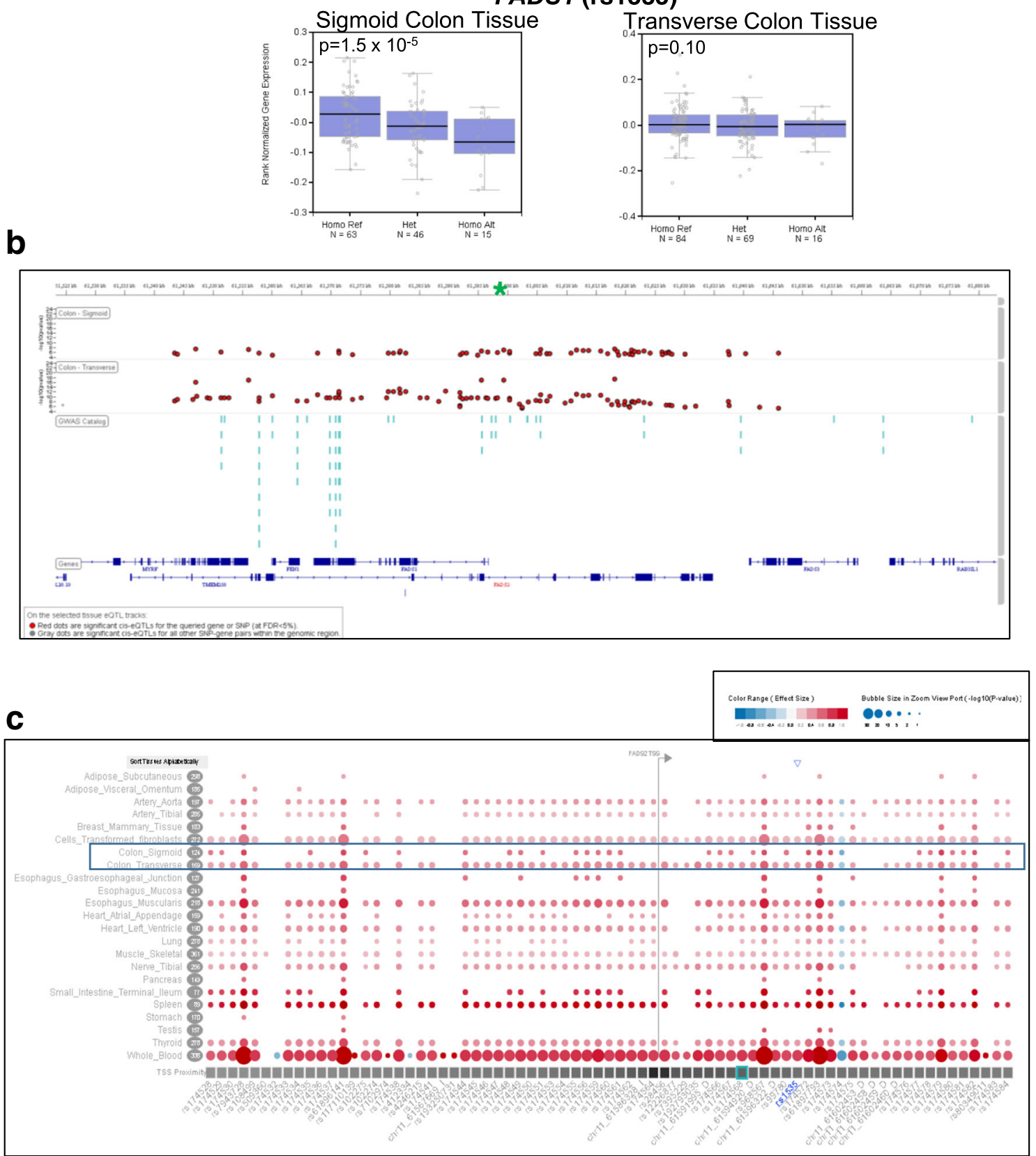

Fig. 1 (See legend on next page.) 
(See figure on previous page.)

Fig. 1 eQTL for rs1535 in Normal Sigmoid and Transverse Colon Tissue. a Box plots of gene expression profiles for FADS2 and FADS1 expression by genotype in normal sigmoid and transverse colon tissue. Reference Allele (risk allele) = A; Alternate Allele = G. b cis-eQTLs (+/- 1 Mb window) for FADS2 in normal sigmoid and transverse colon tissue. rs1535 is indicated by the green asterisk (*). c cis-eQTLs for FADS2 in 23 different tissue types. Bubble size represents -log10(p-value) and color and shading of the bubble represents effect size of the cis-eQTL

H3K27ac_Enh) suggest transcriptional enhancer and promoter activity for this locus in normal tissue from the colon, as well as from other sites of the gastrointestinal tract. In addition, there were two SNPs (rs11213823 and rs7130173) in high LD $\left(r^{2}>0.8\right.$; Europeans) that also displayed promoter and enhancer histone marks as well as multiple transcription factor binding ability in ChIP seq assays. Based on chromatin marks and ChIP seq data, there is a strong indication that two SNPs - rs11213823 $\left(\mathrm{r}^{2}=0.92\right.$; Europeans) located in the 5'-UTR of the COLCA2 gene and rs7130173 $\left(r^{2}=0.93\right.$ Europeans) located in the intron of C11orf53 - are located in a region of transcriptional regulatory activity. In addition, both SNPs are also significant ciseQTLs for COLCA2, COLCA1, and C11orf53.

\section{rs2427308}

The risk variant is located at $20 \mathrm{q} 13$, is a significant ciseQTL $\left(p=7.60 \times 10^{-11}\right)$ in the normal sigmoid colon tissue for the Cdk5 and Abl enzyme substrate 2 (CABLES2) gene. The risk allele is associated with lower expression levels of $C A B L E S 2$ in the normal sigmoid colon tissue compared to the reference allele, with an effect size of ES $=0.76$ (Fig. 3a). The risk variant is located in intron 4 of the CABLES2 gene. CABLES2 has multiple cis-eQTLs in normal sigmoid colon tissue and rs2427308 is not the most significant cis-eQTL for this gene. Another SNP (rs2427312) in high LD $\left(\mathrm{r}^{2}=0.85\right.$; European) with risk variant rs2427308, is the most significant cis-eQTL ( $p=$ $3.8 \times 10^{-13}$; $\mathrm{ES}=0.93$ ) for CABLES2 in this tissue (Fig. $3 \mathrm{~b}$ ). The two SNPs are 1.1 Kb apart, with rs2427312 located in intron 3 of the CABLES2 gene. Based on the GTEx analysis of multiple tissue types $(n=44)$, in addition to the sigmoid colon tissue, rs2427308 is a significant cis-eQTL for $C A B L E S 2$ in several tissues, including the esophagus, arteries, heart, nerve, and skin (Fig. 3c). rs2427308 is also a significant cis-eQTL for the neighboring genes, LAMA5 in transformed fibroblasts and esophagus, and the RP11157P1.5 gene in the heart and liver. CABLES2 has a Cterminal cyclin-box-like domain and has been shown to bind to $\mathrm{Cdk} 3, \mathrm{Cdk} 5$, and c-Abl $[14,15]$. CABLES2 has also been characterized as a possible tumor suppressor, functioning in both p53-mediated and p53-independent induced apoptosis pathways [16].

We also did a cis-eQTL analysis for rs2427308 in colorectal tumor tissue included in the TCGA dataset. Because the SNP data associated with the TCGA samples did not include rs2427308, a proxy (rs6121558) in high LD $\left(r^{2}=0.94\right)$ was queried. Similar to $r 2427308$, the
GTEx Project portal showed that the proxy risk allele was also a significant cis-eQTL in normal sigmoid colon tissue. However, it was not a significant cis-eQTL in colorectal tumor tissue for the CABLES2 $(p=0.45)$ gene. Perhaps, the high frequency of copy number alterations at the CABLES2 gene observed in colorectal tumors contributes to the poor correlation with the cis-eQTL in tumor and normal tissue. Based on GISTIC analysis of the TCGA dataset [5], 65\% of the tumors had a copy number gain (137 of 212) and $8 \%$ had an amplification of the CABLES2 gene.

\section{rs34245511}

This risk variant is located at $12 \mathrm{q} 13$ in the intronic region of the LIMA1 gene. This risk allele was not found to be a cis-eQTL for LIMA1 in any of the tissue included in the GTEx Project (including normal colon tissue). However, it was identified as a significant cis-eQTL $(\mathrm{FDR} \leq 0.05)$ for neighboring genes, such as CERS5, COX14, LARP4, ATF1, ASIC1 and DIP2B, in other tissue types but not for normal colon tissue. Tumor tissue was not evaluated because the risk variant (or a proxy, $r^{2}>0.8$ ) was not available for analysis in TCGA.

\section{rs7229639}

In addition to querying for cis-eQTLs for genes containing or flanking the CRC risk alleles, we queried all of the 55 CRC risk alleles for any cis-eQTLs (within $\pm 1 \mathrm{Mb}$ of the transcript start site) in normal sigmoid or transverse colon tissue. Of the 55 risk alleles examined, we found the risk allele rs7229639, located at $18 \mathrm{q} 21$ in an intron of the $S M A D 7$ gene, was a significant cis-eQTL for the lipase $\mathrm{G}$, endothelial type $\left(\right.$ LIPG) gene $\left(p=3.7 \times 10^{-6}\right.$; $\left.\mathrm{ES}=-0.58\right)$ located $>636 \mathrm{~Kb}$ downstream of rs7229639 in the normal sigmoid colon tissue. It was not a significant cis-eQTL for the SMAD7 gene in normal colon tissue or any of the tissue types $(n=44)$ included in the GTEx project. The risk allele is associated with higher expression levels of the LIPG gene in normal sigmoid colon tissue.

\section{cis-eQTL of missense risk variant, rs3184504}

The missense risk allele, rs3184504, located at $12 \mathrm{q} 24$ is a coding SNP in exon 3 of the SH2B adaptor protein 3 (SH2B3) gene. The predicted effect of this missense mutation using the PolyPhen2 analysis tool indicates that this mutation, resulting in a Trp262Arg substitution, has a "benign" effect on protein function. In our analysis, the risk allele was not identified as a significant cis-eQTL for $S H 2 B 3$ 


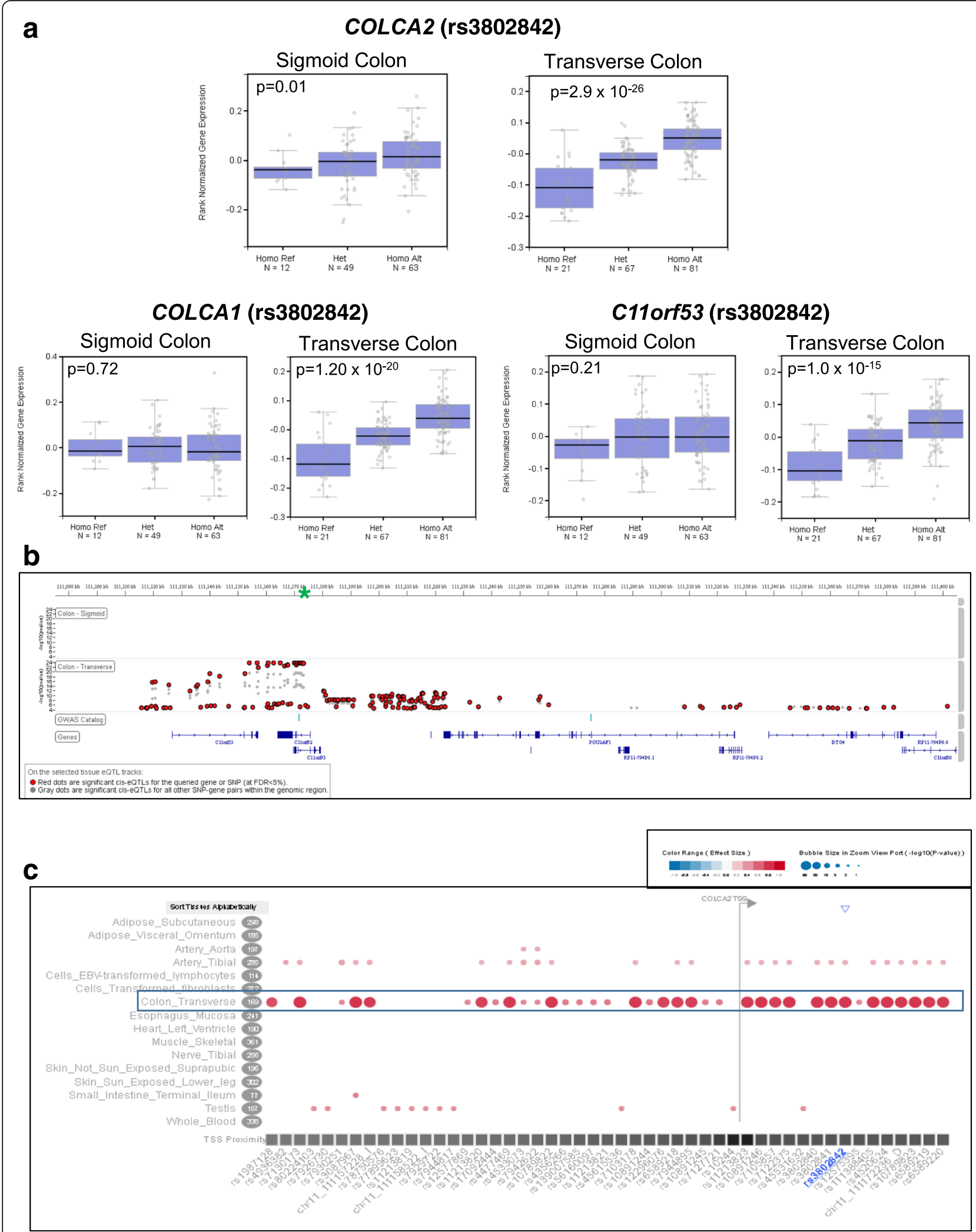

Fig. 2 (See legend on next page.) 
(See figure on previous page.)

Fig. 2 eQTL for rs3802842 in Normal Sigmoid and Transverse Colon Tissue. a Box plots of gene expression profiles for COLCA2, COLCA1, and c110rf53, expression by genotype in normal sigmoid and transverse colon tissue. Reference Allele (risk allele) $=C$; Alternate Allele $=$ A. $\mathbf{b}$ cis-eQTLs (+/- $1 \mathrm{Mb}$ window) for COLCA2 in normal sigmoid and transverse colon tissue. rs3802842 is indicated by the green asterisk $\left(^{*}\right)$. c cis-eQTLs for COLCA2 in 16 different tissue types. Bubble size represents - $\log 10$ ( $p$-value) and color and shading of the bubble represents effect size of the cis-eQTL

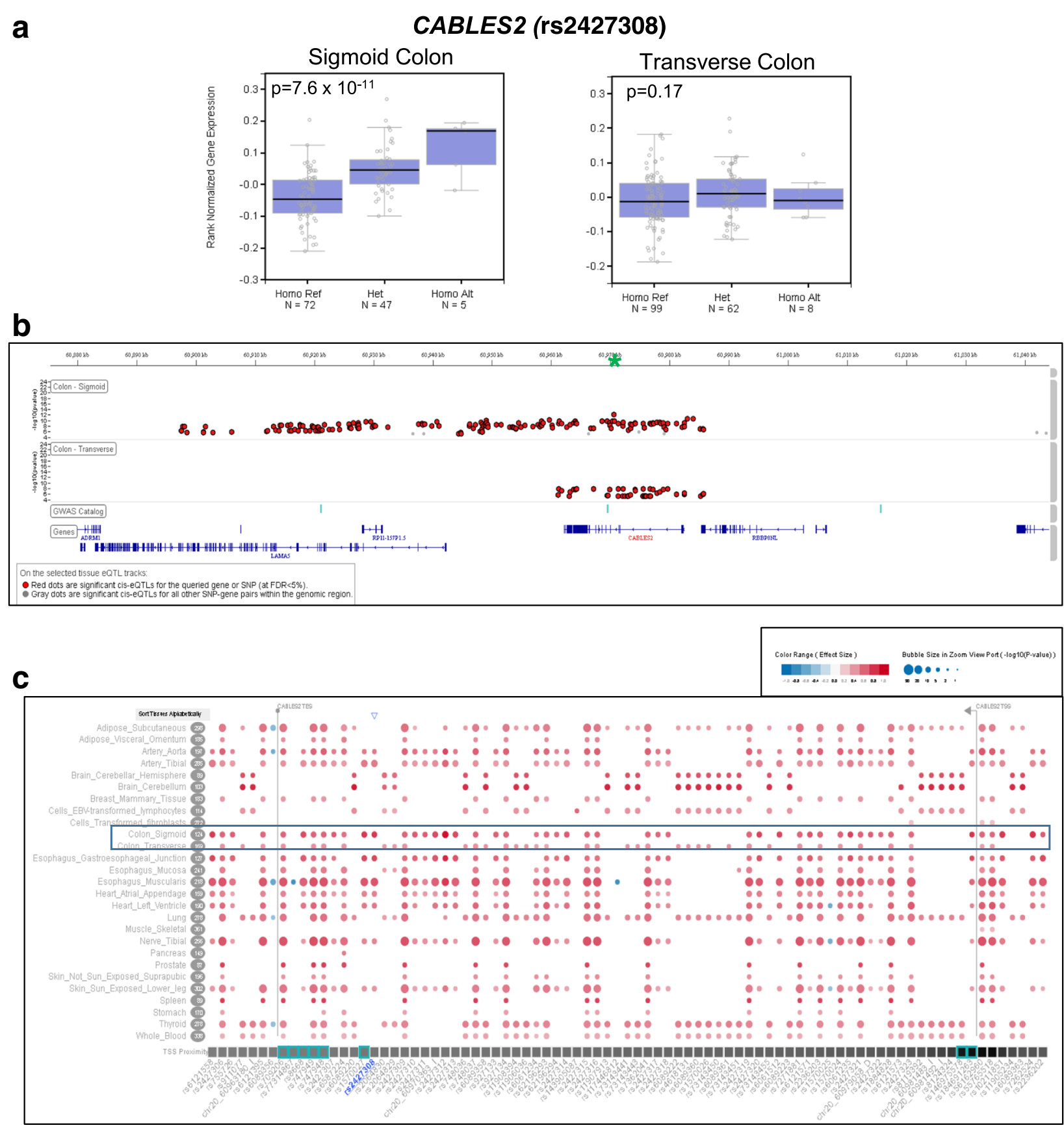

Fig. 3 eQTL for rs2427308 in Normal Sigmoid and Transverse Colon Tissue. a Box plots of gene expression profiles for CABLES2 expression by genotype in normal sigmoid and transverse colon tissue. Reference Allele (risk allele) $=\mathrm{C}$; Alternate Allele $=\mathrm{T}$. $\mathbf{b}$ cis-eQTLs $(+/-1 \mathrm{Mb}$ window) for CABLES2 in normal sigmoid and transverse colon tissue. rs2427308 is indicated by the green asterisk (*). c cis-eQTLs for CABLES2 in 27 different tissue types. Bubble size represents - $\log 10$ ( $p$-value) and color and shading of the bubble represents effect size of the cis-eQTL 
in normal colon sigmoid $(p=0.19)$ or transverse $(p=0.47)$ tissue. Interestingly, it was a significant cis-eQTL for the $A L D H 2$ gene in skin tissue $\left(p=2.80 \times 10^{-8}\right)$, indicating that the missense risk allele in the coding region of the $S H 2 B 3$ gene has the potential to impact the expression of a neighboring gene in specific tissue types.

\section{Discussion}

In this analysis, we evaluated the genes containing, or neighboring, the $55 \mathrm{CRC}$ risk variants identified by GWAS to date for functional interactions through gene ontology enrichment and pathway analyses. The KEGG Pathway analysis revealed a six-fold enrichment for nine of the 65 genes queried are part of the Pathways in Cancer $\left(p\right.$-value $\left.=2.67 \times 10^{-5}\right)$. We also queried the GTEx Project and TCGA databases to identify cis-eQTLs linking the risk alleles and expression patterns of these genes. Interestingly, none of the nine genes enriched in this pathway were identified to have significant eQTLs with the risk alleles in the normal colon (sigmoid or transverse) or colorectal tumor tissue.

We also conducted eQTL analyses for each of the CRC risk variants $(n=55)$ for functional associations with genes containing the risk alleles (coding or intronic SNPs) or with immediate neighboring genes (intergenic SNPs). For each of these risk variants, or SNPs in high LD with them, we utilized normal tissue expression data available through the GTEx Project portal and colorectal tumor tissue available through TCGA to identify significant (FDR $\leq$ 0.05 ) cis-eQTLs in normal colon (sigmoid and transverse), followed up by the characterization of their effect in colorectal tumor tissue. We identified 4 intronic risk alleles that were significant cis-eQTLs in normal colon (sigmoid or transverse) tissue.

The most significant cis-eQTL that we identified was the risk allele, rs3802842, located at 11q23. It was associated with expression of COLCA2, COLCA1, and c11orf53 in normal transverse colon tissue but not in sigmoid colon or colorectal tumor tissue. This SNP is located in the intronic region of the overlapping genes COLCA 2 and COLCA1. The two genes are transcribed from opposite strands, and C11orf53 is $>55 \mathrm{~Kb}$ upstream of rs3802842, neighboring COLCA1. This risk allele is associated with lower expression of all three regulated genes in both normal and tumor tissue. This cis-eQTL has also been previously reported by several groups for normal colon tissue [17-20] and normal rectal tissue [19]. In addition, immunohistochemical evaluation of protein expression profiles were recently reported for COLCA 1 and COLCA2 in normal colon tissue [18]. COLCA1 protein was detected in the lamina propria, extracellularly between epithelial cells, and in immune cells (eosinophils, mast cells, neutrophils, macrophages, and dendritic cells). COLCA2 is expressed in both immune and epithelial cells. Peltekova et al. observed lower levels of COLCA 2 and COLCA1 protein expression in colon tissue from individuals homozygous for the risk allele, consistent with our cis-eQTL results, supporting the observation that the risk allele is associated with lower expression levels of COLCA2 and COLCA1 [18].

In addition to the risk allele (rs3802842), multiple SNPs in high LD are also significant cis-eQTLs for the three genes (COLCA2, COLCA1, and C11orf53) (Fig. 2b) and, as previously reported by Closa et al. 2014 [17], our analysis indicated that rs3802842 was not the most significant cis-eQTL in the region. In fact, rs7130173, a SNP in high LD $\left(\mathrm{r}^{2}=0.94\right)$ with the risk allele had a stronger association with COLCA2 expression and equivalent associations with COLCA1 and C11orf53 expression compared to rs3802842. The rs7130173 locus also demonstrated histone modification marks in normal colon tissue, suggesting that the locus has transcriptional enhancer and promoter activity [21]. However, in addition to the histone marks at the rs7130173 locus, 4 transcription factors (CTCF, SMC3, RAD21, YY1) were shown to be capable of binding to this locus based on ChIP-Seq experiments. Another SNP in high LD $\left(\mathrm{r}^{2}=\right.$ 0.92; Europeans) with rs3802842, and located in the 5'UTR of the COLCA2 gene, rs11213823, also demonstrates a high likelihood of transcriptional regulatory activity, with histone marks and 6 transcription factors (CTCF, RAX5C20, RAD21, POL2, TAF1, HEY1) capable of binding to the locus and is also a significant cis-eQTL $\left(p=6.2 \times 10^{-26}\right)$ for COLCA2 in the normal transverse colon tissue. These data suggest that either, or both, of these two SNPs could be the functional SNP regulating expression of the three genes, primarily COLCA2. In addition, of the 44 tissue types analyzed in the GTEx Project, these significant cis-eQTLs observed in the normal transverse colon tissue had a strong expression association predominantly in colon tissue and not in the other tissue types (Fig. 2c).

The COLCA2 and COLCA1 genes are a highly conserved, with multiple orthologs for both genes - with 160 orthologs for COLCA2, from coelacanths and Xenopus to primates and 21 orthologs for COLCA1, from bats to primates. However, their function has not yet been well characterized. Since lower expression levels of COLCA2 and COLCA1 is associated with the risk allele (Fig. 2a) and lower expression levels of COLCA2 and $C O L C A 1$ were observed in colorectal tumors versus normal tissue (Additional file 4: Figure S2). It is plausible that COLCA2 and COLCA1 both function as a tumor suppressor gene, potentially by mediating immune cell function in the colon tissue.

The intronic risk allele, rs1535 was identified as a significant cis-eQTL for the FADS2 gene in normal transverse colon tissue $\left(p=1.8 \times 10^{-10} ; \mathrm{ES}=0.36\right)$ and although the 
association for normal sigmoid colon tissue was not statistically significant (FDR $>0.05)$, the strong $p$-value $(p=4.0 \times$ $10^{-5}$; ES $=0.42$ ) suggests that rs1535 may also be a ciseQTL for sigmoid colon tissue, with lower levels of FADS2 gene expression being associated with the risk allele. This cis-eQTL was also observed in colorectal tumor tissue by Zhang et al. [22]. We also observed a strong indication for association between rs1535 with FADS2 expression ( $p=$ $1.51 \times 10^{-4}$ ) in colorectal tumor tissue; however this association did not meet the significance cut-off of FDR $\leq 0.05$ after multiple text correction. Interestingly, rs1535 is also a methylation-QTL (meQTL) in lymphocytes: its genotypes, or genotypes at proxy SNPs rs174549 $\left(\mathrm{r}^{2}=0.80\right)$, rs174548 $\left(r^{2}=0.78\right)$ and $\mathrm{rs} 174537\left(\mathrm{r}^{2}=0.94\right)$, are associated with methylation levels at various CpG sites annotated to FADS2, spanning its promoter region, first exon and body region [23]. Notably, the methylation levels at cg06781209, located within 1500 bp of FADS2's transcription start site, increase with the number of risk alleles [23], consistent with the corresponding reduction in gene expression that we observed. $F A D S 2$, and a gene family member, $F A D S 1$, are rate-limiting enzymes that function in the biosynthesis pathway for PUFA conversion and are recognized as the main determinants of PUFA levels. rs1535 was not identified as a statistically significant cis-eQTL for FADS1 in normal transverse or sigmoid colon tissue; however, the strong $p$-value $\left(p=1.5 \times 10^{-5} ; \mathrm{ES}=-0.39\right)$ suggests that rs1535 may also be a cis-eQTL for FADS1 in normal sigmoid colon tissue. Interestingly, FADS1 gene expression pattern associated with the risk allele is in the opposite direction compared to $F A D S 2$, i.e. higher levels of FADS1 expression is associated with the risk allele (Fig. 1a). In addition, rs1535 demonstrates very poor association with FADS1 expression in the transverse colon tissue $(p=0.10)$, the tissue type that had significant association with rs1535 and FADS2. These cis-eQTL results suggest that the effects of the rs1535 on $F A D S 2$ and FADS1 expression differ in the two colon subsites, with lower FADS2 and higher FADS1 expression levels associated with the risk allele in normal sigmoid colon tissue and robust (higher) FADS2 and minimal change in FADS1 expression in the transverse colon (Fig. 1a). These associated effects on gene expression could potentially result in a disruption to the relative levels of the byproducts along the long-chain PUFA biosynthesis pathway mediated by delta- 6 and delta- 5 desaturase. PUFAs play an important role in multiple biological systems, including the maintenance of cellular membrane lipid-bilayer integrity signaling events [24-26]. Alterations to the activity of the FADS 2 and FADS1 gene products, delta- 6 and delta5 desaturase, respectively, has been associated with several diseases, such as diabetes, cardiovascular disease, inflammation, and cancer (breast, melanoma, lung) [27-30]. Our analysis of $F A D S 2$ gene expression in colorectal tumor versus normal tissue indicate that FADS2 is upregulated in colorectal tumors compared to normal tissue $(p=5.21 \times 10$ ${ }^{-7}$ ) (Additional file 4: Figure S2), supporting the observation that disruption of FADS2 expression may also have an important role in CRC.

There are numerous (147) significant cis-eQTLs for $F A D S 2$ in both normal transverse and sigmoid colon tissue, some cis-eQTLs are located in the FADS2 gene and others in neighboring genes (Fig. 1b). The most significant cis-eQTL for FADS2 in transverse colon tissue was not rs1535, it was $\mathrm{rs61897795}\left(p=2.40 \times 10^{-18} ; \mathrm{ES}=0.64\right)$ which is in intron 5 of the FADS2 gene. These two SNPs have a modest linkage $\left(r^{2}=0.32\right.$; Europeans). The linkage disequilibrium structure is quite variable across the three major racial populations at this locus (Additional file 5: Figure S3). Interestingly, the MAF for rs1535 in Europeans is $0.35,0.57$ for East Asians, and 0.11 in Africans, whereas, the MAF for rs61897795, is 0.14 for Europeans, $<0.01$ for East Asians, and 0.01 for Africans (frequencies based on 1000 Genomes Project Phase 3), and the association with rs1535 and CRC was initially identified in an East Asian population. If rs61897795 is identified as the functional SNP, it may have implications on the role played by FADS2 in affecting risk of CRC among Asians and Africans compared to Europeans.

In addition to CRC, the missense risk allele, rs3184504, has been identified as a risk variant for multiple diseases (diabetes, blood pressure, coronary artery disease, arthritis, hypothyroidism, and myocardial infarction) [31-35]. This SNP was also identified as one of three pleiotropic loci with a significant association with colorectal, lung, and breast cancers [36]. rs3184504 is a missense SNP, resulting in a tryptophan to arginine substitution at position 262, the effects of this missense mutation are predicted to be benign to protein function. In addition, in our cis-eQTL analysis in normal and colorectal tumor tissue, we did not identify rs3184504 as a cis-eQTL for $S H 2 B 3$ in colon tissue or any of the other 42 tissue types included in the GTEx Project, or in colorectal tumor tissue in TCGA. However, in a separate study, Westra $\mathrm{HJ}$ et al. identified rs3184504 as a cis-eQTL for SH2B3 and as a trans-eQTL for 14 unique genes involved in toll-like receptor and interferon- $\gamma$ response signaling in whole blood samples [37]. Since these cis- and trans-eQTL genes are linked to immune cell activity, the biological effects of rs3184504 could be to mediate tumorigenesis (colorectal, lung, and breast) through inflammation [38, 39].

The CRC risk variant, rs7229639, located in an intron of the SMAD7 gene was a significant cis-eQTL for LIPG gene $(p=3.7 \times 10-6)$, but not for SMAD7 $(p=0.57)$, in the normal sigmoid colon tissue. The risk allele is associated with higher expression levels of the LIPG gene in normal sigmoid colon tissue. The LIPG gene encodes for a phospholipase involved in lipoprotein metabolism, particularly high-density lipoprotein (HDL) and vascular biology 
[40, 41]. A recent report by Slebe et al. demonstrated that the increased catalytic activity of LIPG is required for breast cancer cell growth and proliferation because it is responsible for hydrolyzing extracellular phospholipids, from HDL, which are then incorporated into intracellular lipids to provide the necessary lipid precursors for breast cancer cells [42]. Similarly, it is possible that the risk allele is associated with CRC by increasing levels of LIPG in colorectal tumor tissue to supply lipid precursors during tumorigenesis.

Our biological pathway and cis-eQTL analysis with the most recent list of CRC risk variants and genes in proximity to these variants, provide further insight into the potential functional relationship between the risk alleles and gene expression. However, there were limitations with our findings as regulation of gene expression is tissue and context specific, involving multiple levels of coordinated regulatory mechanisms, and the available data may have limitations in capturing these events. We utilized data from the GTEx Project portal, providing us the opportunity to examine the relationship between genotype and gene expression of 44 different tissue types from a total of 7051 samples. However, the GTEx Project only included tissue from the normal sigmoid and transverse colon. Therefore cis-eQTL analysis could only be performed for tissue from these colon subsites. Since only $65 \%$ of CRC originate from these two sites (23\% in the distal colon and $42 \%$ in the proximal colon) [43], we may have missed identification of cis-eQTLs for tissue in other regions of the colon and rectum that CRC can originate in. We also did not identify statistically significant cis-eQTL $(\mathrm{FDR} \leq 0.05)$ in the colorectal tumor tissue dataset despite a similar sample size used in the normal colon tissue analysis. We also did not observe significant cis-eQTLs for the three CRC risk variants (rs10795668, rs4444235, and rs9929218) that we identified in a previous report [44], perhaps due to limited sample size in the earlier report and tumor heterogeneity adding to the limitations to identify statistically significant cis-eQTL in tumor tissue. Copy number alterations at the loci of investigation in the tumor tissue may also complicate cis-eQTL identification and interpretation. This study has identified potential functional SNPs which contribute to CRC risk and tumor biology, however, additional experimental validation will be needed to confirm the role of these SNPs and genes in CRC.

\section{Conclusions}

Our biological pathway and cis-eQTL analysis based on the most recent list of CRC risk variants and proximal genes provide further insight into the potential functional regulatory role for risk alleles and gene expression. The data reaffirm the potential to identify an enrichment for biological processes and candidate causal genes based on expression profiles correlated with genetic risk alleles of colorectal cancer, however, the identification of these significant cis-eQTLs is context and tissue specific.

\section{Additional files}

Additional file 1: Table S1. cis-eQTL for colorectal cancer risk alleles and neighboring genes in normal sigmoid and transverse colon tissue. (XLSX 49 kb)

Additional file 2: Table S2. Transcription regulatory features of intronic colorectal cancer risk alleles and linked variants with significant eQTL of neighboring genes. (XLSX $16 \mathrm{~kb}$ )

Additional file 3: Figure S1. Transcriptional regulatory elements at rs1535 (chr11:61,597,490-61,598,700; hg19). ENCODE analysis of the genomic region containing rs1535 indicate a region with transcriptional regulatory activity based on DNAse sensitivity, transcription factor binding (POLR2A and ESR), and histone marks at the locus. (PPTX $111 \mathrm{~kb}$ )

Additional file 4: Figure S2. Cis-eQTL in colorectal tumor tissue and colorectal tumor versus normal tissue gene expression profiles. Box plots of gene expression profiles for FADS2, COLCA2, COLC1, and CABLES2 expression by genotype (cis-eQTL) in colorectal tumor tissue (left column). Box plots of colorectal tumor versus normal tissue gene expression profiles for FADS2, COLCA2, COLC1, and CABLES2 (right column). Indicated proxy SNPs used when SNP data available for the TCGA samples did not include genotypes of risk variants. (PPTX $170 \mathrm{~kb}$ )

Additional file 5: Figure S3. Linkage disequilibrium blocks of the rs1535 (11q12) locus. Linkage disequilibrium blocks $\left(r^{2}\right)$ of the genomic region $(100 \mathrm{~Kb}$ ) containing the risk variant, rs1535 (indicated by the red *) for the three major racial populations (Europeans, CEU; African, YRI; Asian, HCB). LD blocks were generated with the Genome Variation Server (GVS) tool (www.gvs.gs.washington.edu; dbSNP build 144). (PPTX $626 \mathrm{~kb}$ )

\section{Abbreviations}

ChIP: Chromatin immunoprecipitation; CRC: Colorectal cancer; DAVID: Database for Annotation Visualization and Integrated Discovery; ENCODE: Encyclopedia of DNA Elements; eQTL: Expression quantitative trait loci; GTEx: Genotype-Tissue Expression; GWAS: Genome-wide association studies; KEGG: Kyoto Encyclopedia of Genes and Genomes; TCGA: The Cancer Genome Atlas

\section{Acknowledgements}

None.

\section{Funding}

No funding was obtained for this study.

Availability of data and materials

Availability of the data and materials, through public databases and analysis tools are outlined in the Materials and Methods section.

\section{Authors' contributions}

LWML is the first and corresponding author. She has made contributions to the conception, data acquisition, analysis and interpretation of the results, and drafting of the manuscript. She is primarily responsible for the preparation of the manuscript submission and publication process. ML is a coauthor. He contributed to the data acquisition, analysis, and reporting of eQTL and tumor vs. normal expression profiles from the TCGA dataset. He also contributed to the overall concept of the study and analysis strategy. LLM is the senior coauthor. He contributed to the study concept, interpretation, and writing of the manuscript.

\section{Competing interests}

The authors declares that they have no competing interests.

Consent for publication

Not applicable (our datasets do not contain any identifiers of individual persons' data).

Ethics approval and consent to participate

Not applicable (the data was available through public database sources). 


\section{Publisher's Note}

Springer Nature remains neutral with regard to jurisdictional claims in published maps and institutional affiliations.

\section{Author details}

${ }^{1}$ Cancer Epidemiology Program, University of Hawaii Cancer Center, Honolulu, HI, USA. ${ }^{2}$ Ontario Institute for Cancer Research, MaRS Centre, 661 University Avenue, Suite 510, Toronto, ON M5G 0A3, Canada.

\section{Received: 25 August 2016 Accepted: 2 May 2017}

\section{Published online: 15 May 2017}

\section{References}

1. Welter D, MacArthur J, Morales J, Burdett T, Hall P, Junkins H, Klemm A, Flicek P, Manolio T, Hindorff L, et al. The NHGRI GWAS Catalog, a curated resource of SNP-trait associations. Nucleic Acids Res. 2014;42(Database issue):D1001-1006

2. A Catalog of Published Genome-Wide Association Studies [https://www.ebi. ac.uk/gwas/home]. Accessed April 2016

3. Consortium G. The Genotype-Tissue Expression (GTEx) project. Nat Genet. 2013;45(6):580-5.

4. Rosenbloom KR, Sloan CA, Malladi VS, Dreszer TR, Learned K, Kirkup VM, Wong MC, Maddren M, Fang R, Heitner SG, et al. ENCODE data in the UCSC Genome Browser: year 5 update. Nucleic Acids Res. 2013;41(Database issue):D56-63.

5. The-Cancer-Genome-Atlas-Network. Comprehensive molecular characterization of human colon and rectal cancer. Nature. 2012:487(7407):330-7.

6. Storey JD, Tibshirani R. Statistical significance for genomewide studies. Proc Natl Acad Sci U S A. 2003;100(16):9440-5.

7. Ward LD, Kellis M. HaploReg: a resource for exploring chromatin states, conservation, and regulatory motif alterations within sets of genetically linked variants. Nucleic Acids Res. 2012;40(Database issue):D930-934.

8. Ward LD, Kellis M. HaploReg v4: systematic mining of putative causal variants, cell types, regulators and target genes for human complex traits and disease. Nucleic Acids Res. 2016;44(D1):D877-881.

9. Matys V, Fricke E, Geffers R, Gossling E, Haubrock M, Hehl R, Hornischer K, Karas D, Kel AE, Kel-Margoulis OV, et al. TRANSFAC: transcriptional regulation, from patterns to profiles. Nucleic Acids Res. 2003:31(1):374-8.

10. Portales-Casamar E, Thongjuea S, Kwon AT, Arenillas D, Zhao X, Valen E, Yusuf D, Lenhard B, Wasserman WW, Sandelin A. JASPAR 2010: the greatly expanded open-access database of transcription factor binding profiles. Nucleic Acids Res. 2010;38(Database issue):D105-110.

11. Adzhubei IA, Schmidt S, Peshkin L, Ramensky VE, Gerasimova A, Bork P, Kondrashov AS, Sunyaev SR. A method and server for predicting damaging missense mutations. Nat Methods. 2010;7(4):248-9.

12. da Huang W, Sherman BT, Lempicki RA. Systematic and integrative analysis of large gene lists using DAVID bioinformatics resources. Nat Protoc. 2009: 4(1):44-57.

13. da Huang W, Sherman BT, Lempicki RA. Bioinformatics enrichment tools: paths toward the comprehensive functional analysis of large gene lists. Nucleic Acids Res. 2009;37(1):1-13.

14. Sato H, Nishimoto I, Matsuoka M. ik3-2, a relative to ik3-1/cables, is associated with cdk3, cdk5, and c-abl. Biochim Biophys Acta. 2002;1574(2):157-63.

15. Xu S, Li X, Gong Z, Wang W, Li Y, Nair BC, Piao H, Yang K, Wu G, Chen J. Proteomic analysis of the human cyclin-dependent kinase family reveals a novel CDK5 complex involved in cell growth and migration. Mol Cell Proteomics. 2014;13(11):2986-3000.

16. Matsuoka M, Sudo H, Tsuji K, Sato H, Kurita M, Suzuki H, Nishimoto I, Ogata E. ik3-2, a relative to ik3-1/Cables, is involved in both p53-mediated and p53-independent apoptotic pathways. Biochem Biophys Res Commun. 2003;312(2):520-9.

17. Closa A, Cordero D, Sanz-Pamplona R, Sole X, Crous-Bou M, Pare-Brunet L, Berenguer A, Guino E, Lopez-Doriga A, Guardiola J, et al. Identification of candidate susceptibility genes for colorectal cancer through eQTL analysis. Carcinogenesis. 2014;35(9):2039-46.

18. Peltekova VD, Lemire M, Qazi AM, Zaidi SH, Trinh QM, Bielecki R, Rogers M, Hodgson L, Wang M, D'Souza DJ, et al. Identification of genes expressed by immune cells of the colon that are regulated by colorectal cancerassociated variants. Int J Cancer. 2014;134(10):2330-41.

19. Singh T, Levine AP, Smith PJ, Smith AM, Segal AW, Barrett JC. Characterization of expression quantitative trait loci in the human colon. Inflamm Bowel Dis. 2015;21(2):251-6.
20. Hulur I, Gamazon ER, Skol AD, Xicola RM, Llor X, Onel K, Ellis NA, Kupfer SS. Enrichment of inflammatory bowel disease and colorectal cancer risk variants in colon expression quantitative trait loci. BMC Genomics. 2015;16:138.

21. Biancolella M, Fortini BK, Tring S, Plummer SJ, Mendoza-Fandino GA, Hartiala J, Hitchler MJ, Yan C, Schumacher FR, Conti DV, et al. Identification and characterization of functional risk variants for colorectal cancer mapping to chromosome 11q23.1. Hum Mol Genet. 2014;23(8):2198-209.

22. Zhang B, Jia WH, Matsuda K, Kweon SS, Matsuo K, Xiang YB, Shin A, Jee SH, Kim DH, Cai Q, et al. Large-scale genetic study in East Asians identifies six new loci associated with colorectal cancer risk. Nat Genet. 2014;46(6):533-42.

23. Lemire M, Zaidi SH, Ban M, Ge B, Aissi D, Germain M, Kassam I, Wang M, Zanke BW, Gagnon F, et al. Long-range epigenetic regulation is conferred by genetic variation located at thousands of independent loci. Nat Commun. 2015;6:6326

24. Ma DW. Lipid mediators in membrane rafts are important determinants of human health and disease. Appl Physiol Nutr Metab. 2007;32(3):341-50.

25. Merino DM, Ma DW, Mutch DM. Genetic variation in lipid desaturases and its impact on the development of human disease. Lipids Health Dis. 2010;9:63.

26. Stoffel W, Hammels I, Jenke B, Binczek E, Schmidt-Soltau I, Brodesser S, Odenthal $M$, Thevis M. Obesity resistance and deregulation of lipogenesis in Delta6-fatty acid desaturase (FADS2) deficiency. EMBO Rep. 2014;15(1):110-20.

27. He C, Qu X, Wan J, Rong R, Huang L, Cai C, Zhou K, Gu Y, Qian SY, Kang JX. Inhibiting delta-6 desaturase activity suppresses tumor growth in mice. PLoS One. 2012;7(10):e47567.

28. Kroger J, Schulze MB. Recent insights into the relation of Delta5 desaturase and Delta6 desaturase activity to the development of type 2 diabetes. Curr Opin Lipidol. 2012;23(1):4-10.

29. Pender-Cudlip MC, Krag KJ, Martini D, Yu J, Guidi A, Skinner SS, Zhang Y, Qu X, He C, Xu Y, et al. Delta-6-desaturase activity and arachidonic acid synthesis are increased in human breast cancer tissue. Cancer Sci. 2013; 104(6):760-4.

30. Tosi F, Sartori F, Guarini P, Olivieri O, Martinelli N. Delta-5 and delta-6 desaturases: crucial enzymes in polyunsaturated fatty acid-related pathways with pleiotropic influences in health and disease. Adv Exp Med Biol. 2014;824: 61-81.

31. Barber MJ, Mangravite LM, Hyde CL, Chasman DI, Smith JD, McCarty CA Li X, Wilke RA, Rieder MJ, Williams PT, et al. Genome-wide association of lipid-lowering response to statins in combined study populations. PLOS One. 2010;5(3):e9763.

32. Eriksson N, Tung JY, Kiefer AK, Hinds DA, Francke U, Mountain JL, Do CB. Novel associations for hypothyroidism include known autoimmune risk loci. PLoS One. 2012;7(4):e34442.

33. International Consortium for Blood Pressure Genome-Wide Association S, Ehret GB, Munroe PB, Rice KM, Bochud M, Johnson AD, Chasman DI, Smith $A V$, Tobin MD, Verwoert GC, et al. Genetic variants in novel pathways influence blood pressure and cardiovascular disease risk. Nature. 2011 478(7367):103-9.

34. Barrett LW, Fletcher S, Wilton SD. Regulation of eukaryotic gene expression by the untranslated gene regions and other non-coding elements. Cell Mol Life Sci. 2012;69(21):3613-34.

35. Stahl M, Uemura K, Ge C, Shi S, Tashima Y, Stanley P. Roles of Pofut1 and O-fucose in mammalian Notch signaling. J Biol Chem. 2008;283(20):13638-51.

36. Hung RJ, Ulrich CM, Goode EL, Brhane Y, Muir K, Chan AT, Marchand LL, Schildkraut J, Witte JS, Eeles R, et al. Cross Cancer Genomic Investigation of Inflammation Pathway for Five Common Cancers: Lung, Ovary, Prostate Breast, and Colorectal Cancer. J Natl Cancer Inst. 2015;107(11):djv246.

37. Westra HJ, Peters MJ, Esko T, Yaghootkar H, Schurmann C, Kettunen J, Christiansen MW, Fairfax BP, Schramm K, Powell JE, et al. Systematic identification of trans eQTLs as putative drivers of known disease associations. Nat Genet. 2013: 45(10):1238-43.

38. Devalliere J, Charreau B. The adaptor Lnk (SH2B3): an emerging regulator in vascular cells and a link between immune and inflammatory signaling. Biochem Pharmacol. 2011;82(10):1391-402.

39. Luddy KA, Robertson-Tessi M, Tafreshi NK, Soliman H, Morse DL. The role of toll-like receptors in colorectal cancer progression: evidence for epithelial to leucocytic transition. Front Immunol. 2014:5:429.

40. Huang J, Qian HY, Li ZZ, Zhang JM, Wang S, Tao Y, Gao YL, Yin CQ, Que B, Sun T, et al. Role of endothelial lipase in atherosclerosis. Transl Res. 2010; 156(1):1-6.

41. Lamarche B, Paradis ME. Endothelial lipase and the metabolic syndrome. Curr Opin Lipidol. 2007;18(3):298-303. 
42. Slebe F, Rojo F, Vinaixa M, Garcia-Rocha M, Testoni G, Guiu M, Planet E, Samino S, Arenas EJ, Beltran A, et al. FoxA and LIPG endothelial lipase control the uptake of extracellular lipids for breast cancer growth. Nat Commun. 2016;7:11199.

43. Siegel R, Desantis C, Jemal A. Colorectal cancer statistics, 2014. CA Cancer J Clin. 2014:64(2):104-17.

44. Loo LW, Cheng I, Tiirikainen M, Lum-Jones A, Seifried A, Dunklee LM, Church JM, Gryfe R, Weisenberger DJ, Haile RW, et al. cis-Expression QTL Analysis of Established Colorectal Cancer Risk Variants in Colon Tumors and Adjacent Normal Tissue. PLoS One. 2012;7(2):e30477.

45. Peters U, Jiao S, Schumacher FR, Hutter CM, Aragaki AK, Baron JA, Berndt SI, Bezieau S, Brenner H, Butterbach K, et al. Identification of Genetic Susceptibility Loci for Colorectal Tumors in a Genome-Wide Meta-analysis. Gastroenterology. 2013;144(4):799-807. e724.

46. Whiffin N, Hosking FJ, Farrington SM, Palles C, Dobbins SE, Zgaga L, Lloyd A, Kinnersley B, Gorman M, Tenesa A, et al. Identification of susceptibility loci for colorectal cancer in a genome-wide meta-analysis. Hum Mol Genet. 2014;23(17):4729-37.

47. Houlston RS, Webb E, Broderick P, Pittman AM, Di Bernardo MC, Lubbe S, Chandler I, Vijayakrishnan J, Sullivan K, Penegar S, et al. Meta-analysis of genome-wide association data identifies four new susceptibility loci for colorectal cancer. Nat Genet. 2008;40(12):1426-35.

48. Ma X, Zhang B, Zheng W. Genetic variants associated with colorectal cance risk: comprehensive research synopsis, meta-analysis, and epidemiological evidence. Gut. 2014;63(2):326-36.

49. Schumacher FR, Schmit SL, Jiao S, Edlund CK, Wang H, Zhang B, Hsu L, Huang SC, Fischer CP, Harju JF, et al. Genome-wide association study of colorectal cancer identifies six new susceptibility loci. Nat Commun. 2015;6:7138.

50. Houlston RS, Cheadle J, Dobbins SE, Tenesa A, Jones AM, Howarth K, Spain SL, Broderick $P$, Domingo E, Farrington S, et al. Meta-analysis of three genomewide association studies identifies susceptibility loci for colorectal cancer at 1q41, 3q26.2, 12q13.13 and 20q13.33. Nat Genet. 2010;42(11):973-7.

51. Schmit SL, Schumacher FR, Edlund CK, Conti DV, Raskin L, Lejbkowicz F, Pinchev M, Rennert HS, Jenkins MA, Hopper JL, et al. A novel colorectal cancer risk locus at 4q32.2 identified from an international genome-wide association study. Carcinogenesis. 2014;35(11):2512-9.

52. Jiao S, Hsu L, Berndt S, Bezieau S, Brenner H, Buchanan D, Caan BJ, Campbell PT, Carlson CS, Casey G, et al. Genome-wide search for gene-gene interactions in colorectal cancer. PLoS One. 2012;7(12):e52535.

53. Jia WH, Zhang B, Matsuo K, Shin A, Xiang YB, Jee SH, Kim DH, Ren Z, Cai Q, Long J, et al. Genome-wide association analyses in East Asians identify new susceptibility loci for colorectal cancer. Nat Genet. 2013;45(2):191-6.

54. Dunlop MG, Dobbins SE, Farrington SM, Jones AM, Palles C, Whiffin N, Tenesa A, Spain S, Broderick P, Ooi LY, et al. Common variation near CDKN1 A, POLD3 and SHROOM2 influences colorectal cancer risk. Nat Genet. 2012;44(7):770-6.

55. Cui R, Okada Y, Jang SG, Ku JL, Park JG, Kamatani Y, Hosono N, Tsunoda T, Kumar V, Tanikawa $C$, et al. Common variant in 6q26-q27 is associated with distal colon cancer in an Asian population. Gut. 2011;60(6):799-805.

56. Tomlinson IP, Webb E, Carvajal-Carmona L, Broderick P, Howarth K, Pittman AM, Spain S, Lubbe S, Walther A, Sullivan K, et al. A genome-wide association study identifies colorectal cancer susceptibility loci on chromosomes 10p14 and 8q23.3. Nat Genet. 2008:40(5):623-30.

57. Zanke BW, Greenwood CM, Rangrej J, Kustra R, Tenesa A, Farrington SM, Prendergast J, Olschwang S, Chiang T, Crowdy E, et al. Genome-wide association scan identifies a colorectal cancer susceptibility locus on chromosome 8q24. Nat Genet. 2007;39(8):989-94.

58. Tomlinson I, Webb E, Carvajal-Carmona L, Broderick P, Kemp Z, Spain S, Penegar S, Chandler I, Gorman M, Wood W, et al. A genome-wide association scan of tag SNPs identifies a susceptibility variant for colorectal cancer at 8q24.21. Nat Genet. 2007;39(8):984-8.

59. Tenesa A, Dunlop MG. New insights into the aetiology of colorectal cancer from genome-wide association studies. Nat Rev Genet. 2009;10(6):353-8.

60. Wang H, Burnett $T$, Kono S, Haiman CA, Iwasaki M, Wilkens LR, Loo LW, Van Den Berg D, Kolonel LN, Henderson BE, et al. Trans-ethnic genome-wide association study of colorectal cancer identifies a new susceptibility locus in VTI1A. Nat Commun. 2014;5:4613.

61. Tenesa A, Farrington SM, Prendergast JG, Porteous ME, Walker M, Haq $\mathrm{N}$, Barnetson RA, Theodoratou E, Cetnarskyj R, Cartwright N, et al. Genome-wide association scan identifies a colorectal cancer susceptibility locus on $11 \mathrm{q} 23$ and replicates risk loci at $8 \mathrm{q} 24$ and 18q21. Nat Genet. 2008;40(5):631-7.
62. Tomlinson IP, Carvajal-Carmona LG, Dobbins SE, Tenesa A, Jones AM, Howarth K, Palles C, Broderick P, Jaeger EE, Farrington S, et al. Multiple common susceptibility variants near BMP pathway loci GREM1, BMP4, and BMP2 explain part of the missing heritability of colorectal cancer. PLoS Genet. 2011;7(6):e1002105.

63. Lemire M, Qu C, Loo LW, Zaidi SH, Wang H, Berndt SI, Bezieau S, Brenner H, Campbell PT, Chan AT, et al. A genome-wide association study for colorectal cancer identifies a risk locus in 14q23.1. Hum Genet. 2015;134(11-12):1249-62.

64. Peters U, Hutter CM, Hsu L, Schumacher FR, Conti DV, Carlson CS, Edlund CK, Haile RW, Gallinger S, Zanke BW, et al. Meta-analysis of new genome-wide association studies of colorectal cancer risk. Hum Genet. 2012;131(2):217-34.

65. Broderick P, Carvajal-Carmona L, Pittman AM, Webb E, Howarth K, Rowan A, Lubbe S, Spain S, Sullivan K, Fielding S, et al. A genome-wide association study shows that common alleles of SMAD7 influence colorectal cancer risk. Nat Genet. 2007:39(11):1315-7.

\section{Submit your next manuscript to BioMed Central and we will help you at every step:}

- We accept pre-submission inquiries

- Our selector tool helps you to find the most relevant journal

- We provide round the clock customer support

- Convenient online submission

- Thorough peer review

- Inclusion in PubMed and all major indexing services

- Maximum visibility for your research

Submit your manuscript at www.biomedcentral.com/submit
Biomed Central 